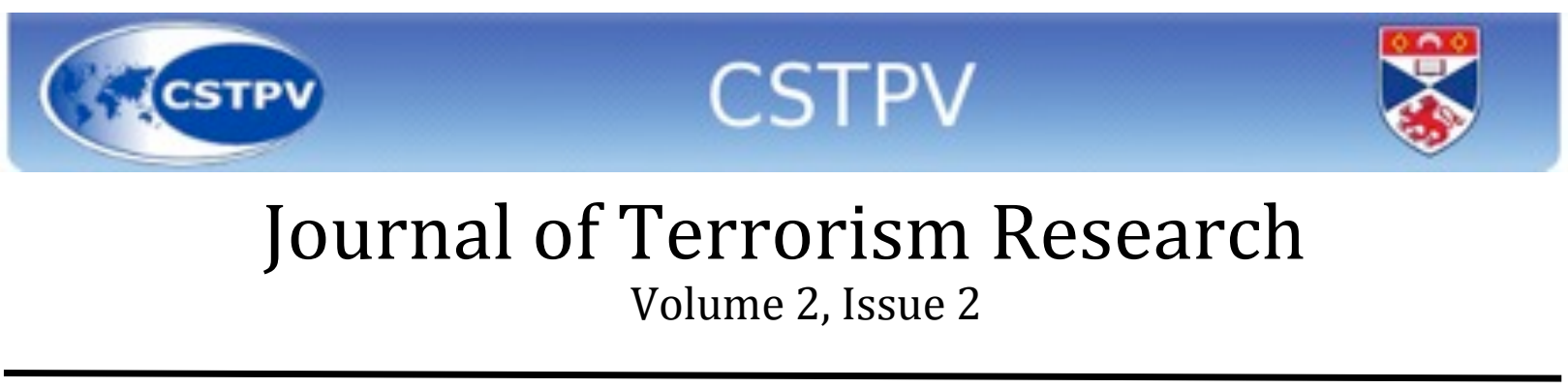

\title{
Managing the change of context in countering terrorism: Death of Bin Laden and the "Arab Spring"
}

\author{
F.Ceren Yazgan Etiz \\ Counsellor \\ Deputy Head of Mission \\ Turkish Embassy in Moscow
}

\section{CSTPV MLitt Distance Learning student}

In world political history, 2011 will be remembered as the year when the leader of the Al Qaida (AQ) terrorist movement was killed and of the so called "Arab Spring", when mass demonstrations in some Arab countries fundamentally challenged the way these countries have been ruled for the past few decades.

In reality there is no connection between these two developments. Yet, they are both likely to have an impact on AQ affiliated or influenced terrorism. The first may have to do mostly with the internal dynamics of AQ and the second is significant in terms of the socio-political context where AQ and its ideology thrive.

Whether AQ as an organization will survive after the death of Bin Ladin and how it will do that is not only a matter of concern for governments fighting against terrorism but also a matter of interest for the students of terrorism studies. It will be a test case for studying the impact of the loss of a leader on the fate of a "fourth wave" terrorist group [1].

In the same vein, the impact of chaotic winds of change in North Africa and Middle East, towards more democracy and freedom on AQ related or influenced terrorism could put many theories on terrorism to test, such as the links between democracy, failed states, relative deprivation and terrorism. [2]

The strategists of AQ can be expected to follow what has been happening in the Arab street, together with other simultaneous developments in the international fora, such as IsraeliPalestinian relations. 


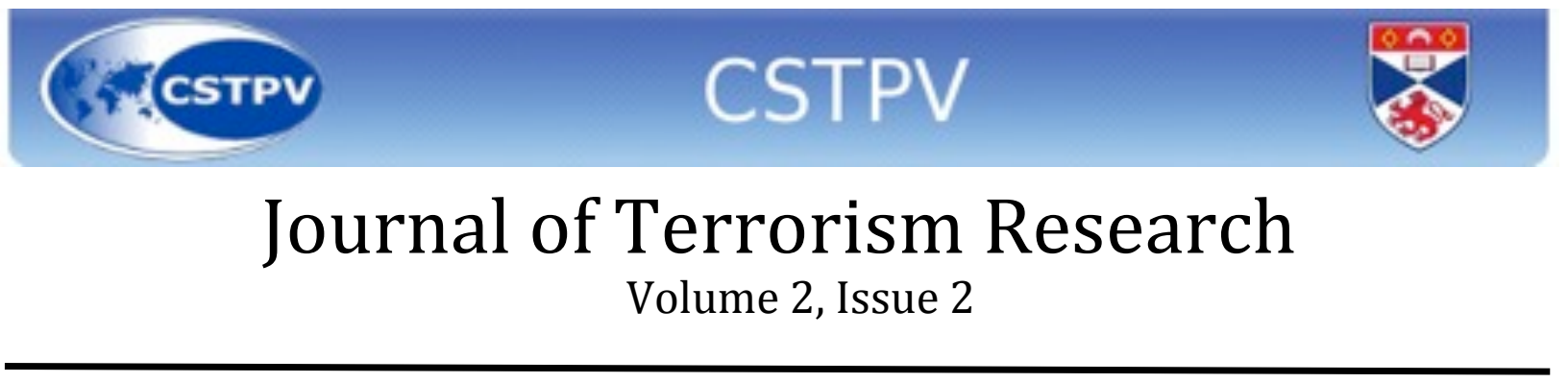

The ideology which they have crafted has so far provided a foundation for the justification of violence to a miniscule number of the frustrated, alienated, seemingly humiliated Muslims of the West as well as the underprivileged Muslims of the developing world. AQ ideology has also managed to inflame Islamophobia in the West, creating new faultlines.

Bin Laden and others, now dead or captured, were not only the founding fathers but also the symbols of this ideology. Bin Laden's death is likely to be turned into a symbol of martyrdom by the remaining AQ strategists, who by now probably have already selected the new "CEO" of AQ Inc.

It would be wise to expect that they are in the planning stage of how to demonstrate to their multiple target audiences that AQ as an organization and as an ideology still lives.

AQ blamed the West and the regimes of the Middle East supported by the West for the sufferings and grievances among the Muslims of the world. Its terrorism targeted Western interests globally. However, its attacks, which were perpetrated in the West, were the most durable in the Western collective memory.

Targeting the West in the West by terrorism was not only aiming at inflicting pain for "revenge", but also a demonstration of power and ensuring more media coverage that helped to increase the impact of terrorist action and to sustain the support of sympathizers / supporters.

This became a preferred tactic particularly due to the reverse correlation between the attention by Western public opinion and the distance of the terrorist threat from the West. Thus, in proof of its survival, AQ will continue to play darts, "bull's eye" being any successful attack in the West.

In the decade that followed 9/11, the West, particularly, Europe, with its resources, systems and institutions managed to harden itself as a target. So, while looking forward to an opportunity to shock the Western public opinion, AQ or groups under its influence will most probably try to sustain their existence by attacking wherever they can. The recent attacks in Pakistan, Iraq, Egypt, Yemen or Morocco could be perceived in that light.

But Europe, too, still has some vulnerabilities.

First, AQ ideology turned out to be appealing to some Muslims of Europe, highlighting understudied problems in Europe's relations with its own Muslim population. [3] 


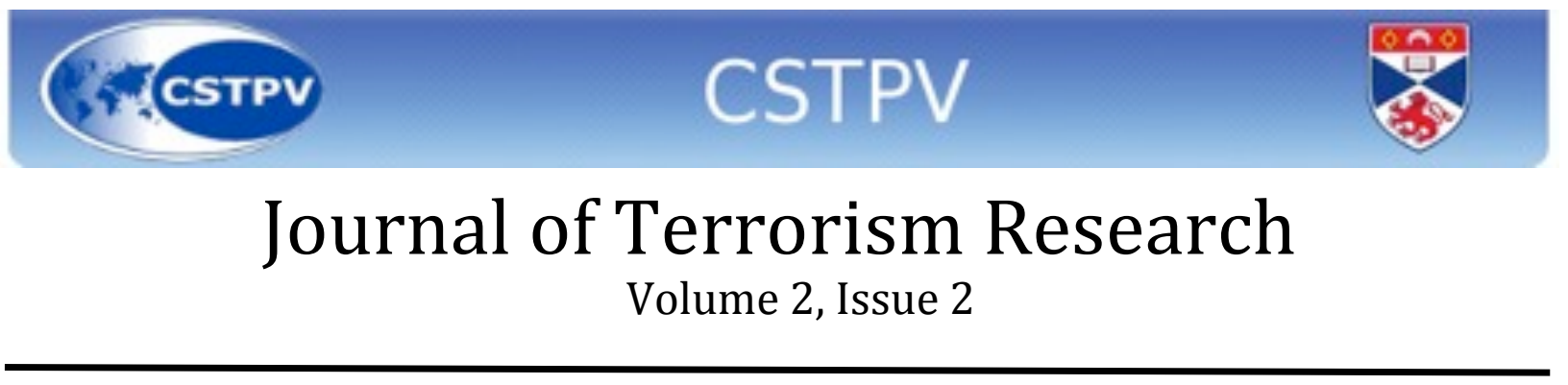

Second, Muslims living in the West have become part of a virtual but global "ummah" thanks to new communication technologies and the way Western governments pursue their foreign policy became closely linked with how Muslims of Europe align their own perceived or real grievances with those in the less developed democracies and war zones.

Third, despite the "war on terrorism", AQ or other terrorist groups affiliated by a similar ideology are still present in certain places of the globe providing technical knowhow to those who for different reasons became dedicated enemies of their own societies and countries.

Therefore, Europe's security from terrorism, in the medium to long run, is closely related to what goes on in the rest of the world.

And the death of Bin Laden cannot help to address any of the vulnerabilities above.

Yet, it might add to sensitivities, if not vulnerabilities. For instance, it can accelerate a premature waning of the Western attention from Afghanistan. This, may lead to the rebuilding of AQ heritage in Afghanistan by its limbs in Europe, Middle East, Sub-continent and Africa. There is no reason why new generations of AQ and Taleban would not find a friend in each other. Should that reunion happens, like in the past, what goes on in Afghanistan would not stay in Afghanistan. After all these years and efforts, it would be a shame to see the "Afghan Arab" phenomenon re-emerging, only this time with links in Europe as well.

If Afghanistan is left to its fate as such, in combination with the memories of Iraq, the old and new elite of the young democracies of the Middle East may conclude that the support and cooperation of the West is limited to its own, as opposed to common, interests. This perception would deepen the rift between "the West" and "the rest", just as AQ strategists would wish for, with implications on international cooperation against terrorism, in addition to other vital issues.

Moreover, the process of change in the Arab world has only just begun. Though it will follow a different course in each country, transition to democracy, change of elite and redistribution of political/economic power is likely to create in each country some pockets of dissatisfied, frustrated or disillusioned population. AQ should be expected to try to win them over. To this end AQ strategists will watch and try to sabotage or take advantage of the "Arab Spring" and the way it is handled by the West.

AQ will count on the impatience, lack of funds, double standards, patronizing attitudes, narrowed interests on the part of Western Governments as well as social fragmentation, 


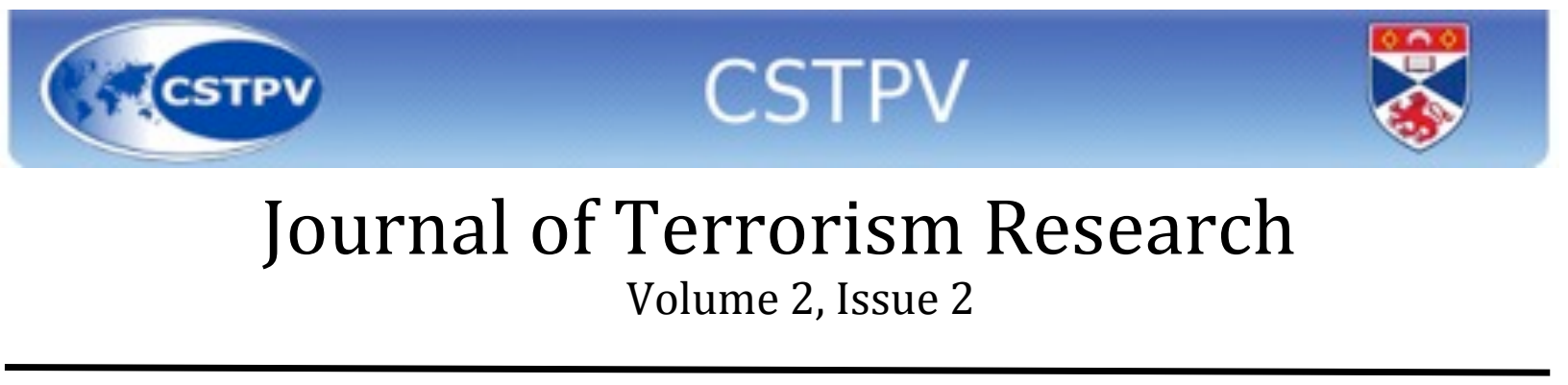

democratic challenges, institutional and economic weaknesses of the Governments of the region for reinforcing and spreading its ideology as well as recruiting new cadres.

While even the most optimist would admit that the death of Bin Laden cannot bring about the end of the AQ terrorist threat by itself, the worst pessimist would agree that this is an opportunity that could weaken AQ and disenchant its supporters. The contextual changes, such as the "Arab Spring" should be properly managed, to seize that opportunity.

\section{Notes}

[1] Rappoport, D.C. (2003) The Four Waves of Rebel Terror and September 11 in The New Global Terrorism : Characteristics, causes , controls (ed) Kegley, C.W Jr. New Jersey, Prentice Hall.

[2] Richardson, L. (2006) The Roots of Terrorism / edited by Louise Richardson Routledge, New York ; Abingdon [England]:

[3] Taarnby, M. (2007) Understanding Recuitment of Islamist Terrorists in Europe, in Mapping Terrorism Research, State of the art, gaps and future direction, (ed) Ranstorp, M. (2007), Oxon. Routledge,

Disclaimer: The views reflected in this opinion piece are author's personal views and do not bind the Ministry of Foreign Affairs of Turkey in any way. 